\title{
Comparative intraocular penetration of topical and injected cefuroxime
}

\author{
C D G Jenkins, S J Tuft, G Sheraidah, D A McHugh, R J Buckley
}

\begin{abstract}
Aims-The choice of a prophylactic antibiotic for cataract surgery is dependent on its antibacterial activity and tissue penetration. The influence of the route and timing of administration of cefuroxime on its intraocular concentrations was examined.

Methods-120 patients were recruited before cataract surgery into a prospective trial to compare the anterior chamber concentration of cefuroxime at a fixed time after adminstration by three routes. In a further 110 patients, the interval before sampling was varied in order to permit an examination of the kinetics of penetration. In another 10 patients, cefuroxime was given topically at the completion of surgery to assess the effect of a corneal wound on aqueous penetration. Cefuroxime concentrations were measured by high performance liquid chromatography on $0.2 \mathrm{ml}$ samples of aqueous aspirated from the anterior chamber. Mean aqueous concentrations of cefuroxime for each group were compared using Student's $t$ test.
\end{abstract}

Results-After $25 \mathrm{mg}$ cefuroxime, mean aqueous concentrations increased in the order forniceal $(<0.01 \mu \mathrm{g} / \mathrm{ml})<$ topical $(0.18 \mu \mathrm{g} / \mathrm{ml})$ < subconjunctival $(2.31 \mu \mathrm{g} / \mathrm{ml})$ when sampled 12-24 minutes after administration. Aqueous concentrations of cefuroxime reached a peak between 80 and 110 minutes after both forniceal and peribulbar injection but were still rising at this time after subconjunctival injection. Topical application of $12.5 \mathrm{mg}$ cefuroxime to eyes with a $10 \mathrm{~mm}$ corneal wound resulted in a mean aqueous concentration of $9.34 \mu \mathrm{g} / \mathrm{ml}$.

Moorfields Eye Hospital, City Road, London EC1V 2 PD C D J Jenkins S J Tuft

G Sheraidah

D A McHugh

R J Buckley

Correspondence to: Dr C D G Jenkins.

Accepted for publication 28 March 1996

Conclusion-In the intact eye, only subconjunctival injection resulted in clinically significant aqueous concentrations of cefuroxime $(>1 \mu \mathrm{g} / \mathrm{ml})$ between 12 and 24 minutes after administration. For all routes, maximal aqueous concentrations were delayed by at least 80 minutes from administration. In the presence of a corneal wound, high aqueous levels of cefuroxime were rapidly attained after topical application.

(Br F Ophthalmol 1996;80:685-688)
Prophylactic antibiotics are administered to decrease the incidence of infectious endophthalmitis, but their benefits have never been proved in a controlled clinical trial. ${ }^{1}$ Preoperative antibiotic therapy should theoretically reduce periorbital bacterial flora and therefore reduce autologous bacterial contamination at the time of surgery, but a large uncontrolled study only reported a small decrease in the incidence of endophthalmitis after topical chloramphenicol. ${ }^{2}$ Another important action of antibiotic prophylaxis is to provide postoperative wound and intraocular antibiotic concentrations sufficient to kill any organisms introduced at the time of surgery. The choice of antibiotic should, therefore, be determined by its activity against potential pathogens of postoperative infection (Tables 1 and 2) and its bioavailability.

The optimum dose and route of administration of cefuroxime to the human eye are not known. This study set out (i) to compare how the route of antibiotic delivery influences intraocular penetration in uninflamed human eyes, (ii) to ascertain the dose of cefuroxime necessary to attain clinically significant aqueous levels for each route, and (iii) to determine how a corneal wound might influence cefuroxime absorption.

Table 1 Organisms cultured in postoperative endophthalmitis

\begin{tabular}{lll}
\hline Organism & $\begin{array}{l}\text { Driebe et al } \\
(n=63)\end{array}$ & $\begin{array}{l}\text { Puliafito et al }{ }^{14} \\
(n=17) \% \text { cases }\end{array}$ \\
\hline Sepidermidis & 38 & 58 \\
S aureus & 21 & 12 \\
Streptococci & 11 & - \\
Diphtheroids & - & 6 \\
Proteus & 6 & 6 \\
Serratia & 6 & 6 \\
Propionibacterium & 5 & - \\
Pseudomonas & 3 & 6 \\
\hline
\end{tabular}

Table 2 Minimum inhibitory concentration (MIC ${ }^{90}$ ) of cefuroxime to organisms commonly cultured in postoperative endophthalmitis $15-17$

\begin{tabular}{ll}
\hline & $M I C^{90}(\mu \mathrm{g} / \mathrm{ml})$ \\
\hline S epidermidis & 8 \\
$S$ aureus & 0.25 \\
$S$ pneumoniae & $<0.125$ \\
Pseudomonas aeruginosa & $>125$ \\
Propionibacterium acnes. & $(0.1-0.2)^{\star}$ \\
\hline
\end{tabular}

${ }^{\star} \mathrm{MIC}_{90}$ to cephazolin. 
Table 3 Aqueous concentrations 12-24 minutes following varying doses of cefuroxime

\begin{tabular}{lcccc}
\hline Route & $\begin{array}{l}\text { Dose } \\
(\mathrm{mg})\end{array}$ & $\begin{array}{l}\text { Number } \\
\text { of patients }\end{array}$ & $\begin{array}{l}\text { Mean } \\
(\mu \mathrm{g} / \mathrm{ml})\end{array}$ & $\begin{array}{l}\text { SEM } \\
(\mu \mathrm{g} / \mathrm{ml})\end{array}$ \\
\hline Topical & 2.5 & 10 & 0.03 & 0.01 \\
& 12.5 & 10 & 0.05 & 0.02 \\
Forniceal & 25 & 10 & 0.18 & 0.05 \\
& 12.5 & 10 & $<0.01$ & 0.00 \\
& 25 & 10 & $<0.01$ & 0.00 \\
& 62.5 & 10 & 0.1 & 0.04 \\
Subconjunctival & 125 & 8 & 0.86 & 0.28 \\
& 250 & 7 & 1.02 & 0.43 \\
& 25 & 10 & 1.81 & 0.47 \\
& 62.5 & 10 & 2.31 & 0.71 \\
& 125 & 10 & 12.33 & 2.13 \\
& 12.5 & 20.23 & 4.09 \\
\hline
\end{tabular}

\section{Materials and methods}

The study was divided into three parts. In the first, the dose of cefuroxime given preoperatively by topical, forniceal, and subconjunctival routes was varied. Patients were assigned to each group on a consecutive basis (see Table 3). Aqueous levels of cefuroxime were then measured to determine a suitable fixed dose of cefuroxime for use in the second part of the study, in which samples were taken at one of four time intervals after administration. We also investigated the ocular penetration of cefuroxime by peribulbar injection in this part of the study. The doses used are given in Table 4. In the third part of the study, topical cefuroxime was applied to the wound at completion of surgery.

\section{DRUG DELIVERY}

For topical delivery, a preservative-free solution of $50 \mathrm{mg} / \mathrm{ml}$ cefuroxime (Glaxo) was supplied by the hospital pharmacy. Each drop was assumed to have a volume of $50 \mu \mathrm{l}$ and to contain $2.5 \mathrm{mg}$ cefuroxime. It was deemed impracticable to give the patient more than 10 drops (25 mg cefuroxime) by the topical route. Drops were administered at intervals of $5 \mathrm{~min}$ utes when more than one drop was given, the time interval before sampling being taken from the last drop. For the postoperative penetration study, five drops $(12.5 \mathrm{mg})$ were placed at 5 second intervals onto the superior limbus and aqueous sampled after an interval of 3 minutes.

For injection, a solution of $125 \mathrm{mg} / \mathrm{ml}$ cefuroxime in water was made up in the theatre suite immediately before administration. Subconjunctival cefuroxime was injected under the inferior bulbar conjunctiva approximately 4

Table 4 Aqueous concentration following a fixed dose of cefuroxime

\begin{tabular}{lrrll}
\hline Route and dose & Time $(\mathrm{min})$ & $\begin{array}{l}\text { Number of } \\
\text { patients }\end{array}$ & Mean $(\mu \mathrm{g} / \mathrm{ml})$ & SEM $(\mu \mathrm{g} / \mathrm{ml})$ \\
\hline Topical $25 \mathrm{mg}$ & $12-24$ & 10 & 0.18 & 0.05 \\
Forniceal $125 \mathrm{mg}$ & $120-160$ & 10 & 2.16 & 0.46 \\
& $12-24$ & 10 & 0.86 & 0.28 \\
& $40-60$ & 9 & 0.93 & 0.32 \\
Peribulbar $125 \mathrm{mg}$ & $80-110$ & 9 & 1.57 & 0.60 \\
& $120-160$ & 7 & 0.93 & 0.51 \\
& $12-24$ & 10 & 1.63 & 0.85 \\
Subconjunctival 25 mg & $40-60$ & 10 & 4.74 & 0.94 \\
& $80-110$ & 9 & 6.66 & 1.11 \\
& $120-160$ & 8 & 4.26 & 0.73 \\
& $12-24$ & 10 & 2.31 & 0.71 \\
& $40-60$ & 8 & 2.85 & 0.63 \\
& $80-110$ & 8 & 4.77 & 0.84 \\
& $120-160$ & 9 & 5.65 & 1.08 \\
\hline
\end{tabular}

mm from the limbus; forniceal cefuroxime was injected under the inferior forniceal conjunctiva anterior to the orbital septum; peribulbar cefuroxime was injected through the conjunctiva adjacent to the inferior orbital floor and level with the equator of the globe.

SURGERY, AQUEOUS SAMPLING, AND CEFUROXIME ANALYSIS

A total of 230 patients older than 50 years of age and without a history of previous ocular surgery were recruited into the first two parts of this study. All surgery was performed under local anaesthetic consisting of topical amethocaine and $6 \mathrm{ml}$ of a 50:50 mixture of lignocaine $1 \%$ and bupivacaine $0.5 \%$ given by peribulbar injection. In all patients, extracapsular cataract extraction was employed. A corneal groove was fashioned and a $0.2 \mathrm{ml}$ aqueous sample aspirated via a 27 gauge needle into a $1 \mathrm{ml}$ syringe. The anterior chamber was then reformed with Ringer's saline before proceeding. A further 10 patients were recruited into part 3 of the study, in which the penetration of cefuroxime through a $10 \mathrm{~mm}$ corneal wound sutured with five 10:0 nylon sutures was investigated. Wound integrity was tested before the application of cefuroxime and anterior chamber fluid was aspirated through the wound with a blunt ended 25 gauge cannula. In all patients, samples were transferred to a $500 \mu \mathrm{l}$ Eppendorf vial and stored at $-50^{\circ} \mathrm{C}$. Samples were analysed using a Spherisorb ODS2 high performance liquid chromatography column in conjunction with a range of standard concentrations of cefuroxime reconstituted in water. Samples were not collected from patients assigned to the forniceal mode of drug delivery in whom a bulbar conjunctival bleb was raised. Eighteen of the 230 aqueous samples were collected outside the designated time intervals and were not therefore included in the statistical analysis (Tables 3 and 4). Mean concentrations for these groups were compared using Student's $t$ test.

\section{Results}

At an interval of 12-24 minutes after the administration of $25 \mathrm{mg}$ cefuroxime, the mean aqueous concentration increased in the order forniceal $(<0.01 \mu \mathrm{g} / \mathrm{ml})<$ topical $(0.18 \mu \mathrm{g} / \mathrm{ml})$ $<$ subconjunctival $(2.31 \mu \mathrm{g} / \mathrm{ml})$. Following the injection of $125 \mathrm{mg}$ cefuroxime, the mean aqueous concentration increased in the order forniceal $(0.86 \mu \mathrm{g} / \mathrm{ml})<$ peribulbar (1.63 $\mu \mathrm{g} / \mathrm{ml})$ < subconjunctival $(20.23 \mu \mathrm{g} / \mathrm{ml})$. Only a subconjunctival injection of $\geqslant 0.5 \mathrm{ml}$ cefuroxime $(125 \mathrm{mg} / \mathrm{ml})$ resulted in aqueous levels greater than $8 \mu \mathrm{g} / \mathrm{ml}(12.33 \mu \mathrm{g} / \mathrm{ml}, 95 \%$ confidence interval $8.16-16.5 \mu \mathrm{g} / \mathrm{ml}$ ). By the forniceal route, it was necessary to inject an impractical $2 \mathrm{ml}$ cefuroxime before clinically significant aqueous levels were obtained (1.02 $\mu \mathrm{g} / \mathrm{ml}, 95 \%$ confidence interval $0.18-1.86$ $\mu \mathrm{g} / \mathrm{ml}$ ) (Table 3 and Fig 1).

For all routes of administration, however, peak aqueous levels of cefuroxime occurred considerably later than 12-24 minutes after administration. For example, following topical 


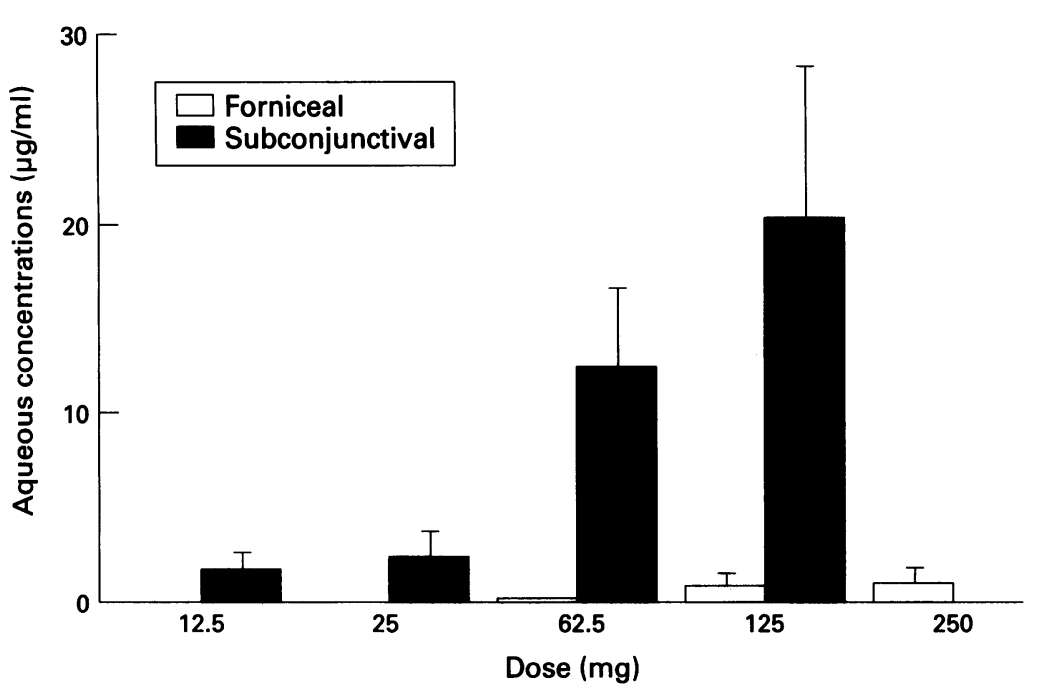

Figure 1 Mean aqueous concentrations of cefuroxime 12-24 minutes after administration. Error bars indicate $95 \%$ confidence intervals.

application, levels increased by a factor of 12 from $0.18 \mu \mathrm{g} / \mathrm{ml}$ to $2.16 \mu \mathrm{g} / \mathrm{ml}$ when sampling was delayed by 2 hours $(p<0.001$, unpaired Student's $t$ test, df 18). After subconjunctival administration, aqueous levels more than doubled between the early and late sampling groups $(2.31 \mu \mathrm{g} / \mathrm{ml}$ to $5.65 \mu \mathrm{g} / \mathrm{ml}, \mathrm{p}=0.001)$. Maximal aqueous concentrations were recorded between 80 and 110 minutes after forniceal and peribulbar injection; at these intervals, aqueous concentrations were still rising following subconjunctival injection (Table 4 and Fig 2).

Following direct topical application of $12.5 \mathrm{mg}$ cefuroxime to a corneal wound, a mean concentration of $9.34 \mu \mathrm{g} / \mathrm{ml}$ (confidence interval $6.62-12.06 \mu \mathrm{g} / \mathrm{ml}$ ) was obtained. As a comparison, a mean level of $0.05 \mu \mathrm{g} / \mathrm{ml}$ (confidence interval $0.01-0.09 \mu \mathrm{g} / \mathrm{ml}$ ) was attained in intact non-inflamed eyes sampled between 12 and 24 minutes after topical application of $12.5 \mathrm{mg}$ cefuroxime.

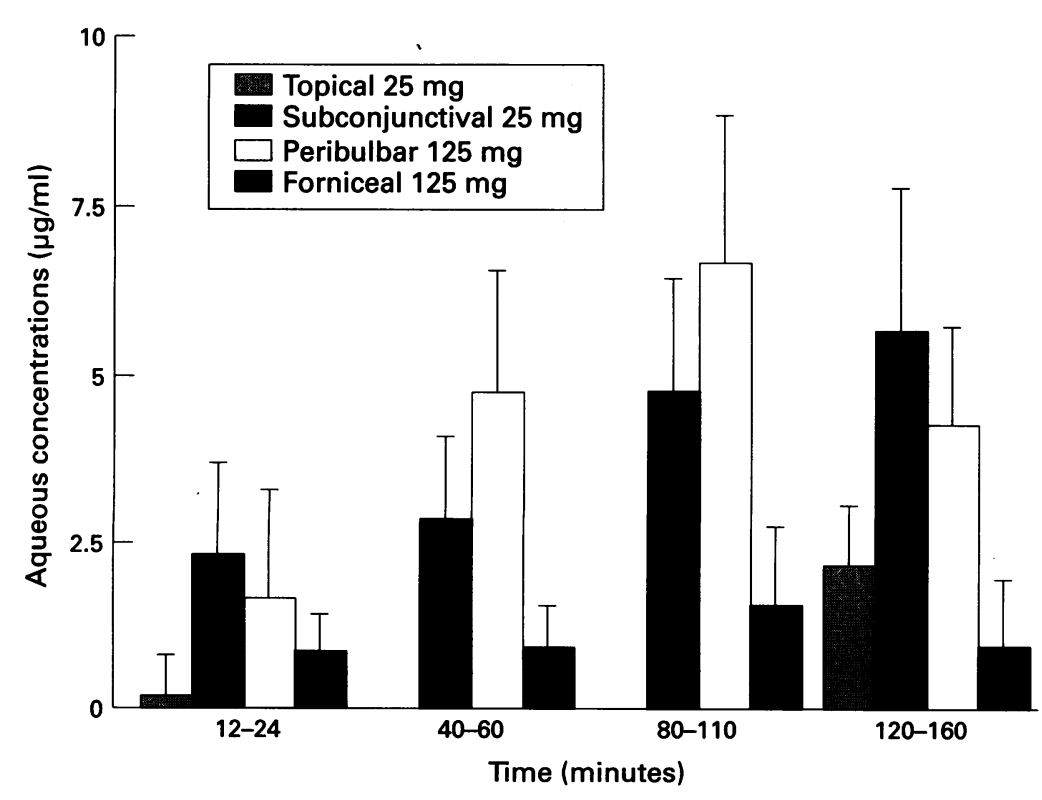

Figure 2 Mean aqueous concentrations of cefuroxime at variable times after administration. Error bars indicate $95 \%$ confidence intervals.

\section{Discussion}

The clinical significance of the results outlined above may be assessed by comparing mean aqueous concentrations of cefuroxime with the MIC $_{90}$ of commonly isolated species in post cataract surgery endophthalmitis (Tables 1 and 2). These figures should only serve as a guide to the in vivo activity of cefuroxime because (i) a tissue environment may interfere with the interaction between the antimicrobial drug and bacteria, (ii) these figures are determined for bacteria in highly specific phases of their growth cycle, (iii) there may be a difference between the bactericidal and bacteriostatic cefuroxime levels for each species, and (iv) the susceptibility of bacteria to cefuroxime may have changed since these studies were published. For $\beta$ lactam antibiotics, such as cefuroxime, it is not always necessary to achieve very high tissue levels, since their bactericidal activity does not increase at levels greater than 2-4 times the $\mathrm{MIC}_{90}$ and it is usually stated that concentrations equivalent to the MIC $_{90}$ are suitable for prophylaxis. ${ }^{3}$ Aqueous levels of $8 \mu \mathrm{g} / \mathrm{ml}$ would therefore be needed for many strains of Staphylococcus epidermidis (Table 2). For the purposes of this study, therefore, we have arbitrarily defined a level of 1 $\mu \mathrm{g} / \mathrm{ml}$ as a clinically significant aqueous concentration and $8 \mu \mathrm{g} / \mathrm{ml}$ as a desirable aqueous concentration for antibiotic prophylaxis with cefuroxime.

We have shown that both route and time of administration influence the attainment of clinically significant mean intraocular levels of cefuroxime. Subconjunctival cefuroxime resulted in the highest aqueous levels of cefuroxime and therapeutic levels were achieved relatively quickly and continued to increase up to 2 hours after surgery. Peribulbar injection resulted in much lower levels and mean aqueous concentrations following forniceal injection were clinically insignificant. Topical cefuroxime only resulted in clinically significant aqueous levels after 2 hours. The mechanism of cefuroxime entry into the eye by these routes is clearly different. We suspect that for topical and forniceal routes of administration, transcorneal penetration is operative. Although forniceal injection bypasses the conjunctival epithelial barrier, it places the antibiotic away from the globe. It is probable that intraocular penetration occurs by leakage through the injection site into the tear film. Following subconjunctival and peribulbar injection, not only is the conjunctival epithelial barrier breached, but the antibiotic is placed adjacent to the sclera, facilitating trans-scleral penetration. In contrast with the intact eye, topical application in the presence of a $10 \mathrm{~mm}$ corneal incision was associated with high aqueous levels of cefuroxime. We believe that surgery disrupts the lipid-rich barrier formed by the corneal epithelium and endothelium, thereby enhancing ocular penetration of cefuroxime.

This study also investigated the effect of time on the intraocular penetration of cefuroxime. Previous studies have used antibiotics and routes of administration that are rarely employed ${ }^{4-6}$ or have studied non-human eyes. ${ }^{7}$ In 
rabbits, maximal aqueous levels after topically applied penicillin were reported after only 30 minutes. ${ }^{8}$ In contrast, the maximal aqueous levels of cefuroxime in humans are not reached for at least 1 hour after administration by all routes. These findings are similar to those reported in the human eye for topically applied prednisolone sodium phosphate, the highest mean aqueous concentrations of which were found between 90 and 240 minutes after application. ${ }^{9}$

Subconjunctival cefuroxime results in the attainment of rapid and sustained clinically useful aqueous concentrations which suggests that subconjunctival cefuroxime followed by intensive topical treatment would result in the rapid onset and subsequent maintenance of high aqueous levels of this antibiotic. Since cefuroxime is an organic anion secreted by the eye, it is conceivable that intraocular concentrations of cefuroxime in non-surgical situations could be enhanced by the use of probenecid..$^{10}$ It is less likely to be of benefit after surgery, however, when the barrier to equilibration across the ocular coats has been compromised.

Conventionally, subconjunctival antibiotics are given at the completion of surgery, which obviates the opportunity to decrease the number of viable bacteria introduced into the eye during surgery. This may explain why most studies have failed to demonstrate any superiority for subconjunctival antibiotic administration over topical administration in preventing postoperative endophthalmitis. ${ }^{11}$ But if subconjunctival antibiotics were to be given preoperatively and thereby reduce bacterial load, the attainment of bactericidal wound and intraocular concentrations postoperatively might be compromised, as a result of antibiotic washout during irrigation and aspiration. We noted, however, that fluid blebs were still present when surgery was performed 2 hours after subconjunctival injection, suggesting that cefuroxime is relatively slowly cleared and that intraocular concentrations might rise again after surgery. Further work should therefore investigate postoperative aqueous levels of cefuroxime after preoperative subconjunctival administration.

We measured aqueous levels in the postoperative period 3 minutes after topical application to the cornea and demonstrated rapid ocular penetration. If it had been possible to sample aqueous at longer intervals after the completion of surgery or after subconjunctival administration, even higher levels might have been obtained. Cefuroxime has been demonstrated to be relatively non-toxic to the human eye $^{12}$ and no adverse reactions were reported with intraocular cefuroxime concentrations as high as $550 \mu \mathrm{g} / \mathrm{ml}$ in the rabbit eye. ${ }^{7}$ Other drugs may be more toxic, and our results suggest that detailed pharmokinetic and experimental toxicity data should be obtained before recommending the administration of any new drug to the eye in the presence of a surgical wound.

This work was sponsored by the locally organised scheme of Moorfields Eye Hospital.

1 Starr MB. Prophylactic antibiotics for ophthalmic surgery. Surv Ophthalmol 1983;27:353-73.

2 Allen HF, Mangiaracine AB. Bacterial endophthalmitis after cataract extraction. II. Incidence in 36,000 consecutive operations with special reference to preoperative antibiotics. Arch Ophthalmol 1974;91:3-7.

3 Vree TB, Hekster YA. Pharmacokinetics and tissue concentrations of cefuroxime. [Review] Pharmaceutisch Weekblad Scientific Edition 1990;12(6A):262-6.

4 Clements DB, Tailor V. A study of aqueous and serum levels of ceftazidime following subconjunctival injection. $\mathrm{Br} \mathcal{F}$ Ophthalmol 1987;71:433-5.

5 Saunders JH, McPherson SD. Ocular penetration of cefazolin in humans and rabbits after subconjunctival injection. Am $\mathcal{F}$ Ophthalmol 1980;89:564-6.

6 Giamarellou H, Kavouklis M, Petrikkos G, Daikos GK Ceftazidime, moxalactam, cefotaxime, and cefuroxime kinetics into the human aqueous humor. F Ocular Ther Surg 1984;3:170-4.

7 Koul S, Philipson A, Philipson BT, Kock E, Nylén P. Intraocular levels of cefuroxime in uniflammed rabbit eyes. Acta Ophthalmol 1990;68:455-65.

8 Oakley DE, Weeks RD, Ellis PP. Corneal distribution of subconjunctival antibiotics. Am $\mathcal{f}$ Ophthalmol 1976;81: 307-12.

9 McGhee CNJ, Noble MJ, Watson DG, Dutton GN, Fern AI, Healey TM, et al. Penetration of topically applied prednisolone sodium phosphate into human aqueous humour. Eye 1989;3:463-7.

10 Axelrod JL, Kochman RS. Cefoxitin levels in human aqueous humor. Am F Ophthalmol 1980;90:388-93.

11 Christy NE, Lall P. Postoperative endophthalmitis following cataract surgery. Effects on subconjunctival antibiotics and other factors. Arch Ophthalmol 1973;90:361-6.

12 Jenkins C, Mcdonnell PJ, Spalton DJ. A randomised single blind trial to compare the toxicity of subconjunctival gentamicin and cefuroxime in cataract surgery. $\mathrm{Br}$ Ophthalmol 1990;74:734-8.

13 Driebe WT, Mandelbaum S, Forster R, Schwartz L, Culbertson W. Pseudophakic endophthalmitis. Ophthalmology 1986;93:442-8.

14 Puliafito CA, Baker AS, Haaf J, Foster CS. Infectious endophthalmitis. Ophthalmology 1982;89:921-9.

15 Kucers A, Bennett N. The use of antibiotics. 3rd ed. London William Heinemann, 1979: 325-58.

16 Eykyn S, Jenkins C, King A, Phillips I. Antibacterial activity of cefuroxime, a new cephalosporin antibiotic, compared with that of cephaloridine, cephalothin, and cefamandole. Antimicrob Agents Chemother 1976;9:690-5.

17 Wang WL, Everett ED, Johnson M, Dean E. Susceptibility of Propionibacterium acnes to seventeen antibiotics. Antimicrob Agents Chemother 1977;11:171-3. 